\title{
Synergistic Effect of Vitamin C with Superparamagnetic Iron Oxide Nanoparticles for Inhibiting Proliferation of Gastric Cancer Cells
}

\author{
Yaser Asefi ${ }^{1, *(\mathbb{D})}$, Reza Fahimi ${ }^{2}$ (D), Saeed Ghorbian ${ }^{1(\mathbb{D}}$ \\ 1 Department of Genetics, Ahar Branch, Islamic Azad University, Ahar, Iran; asefiyaser65@gmail.com (Y.A.); \\ ghorbian20@gmail.com (S.G.); \\ 2 Medical Research Center, Kateb University, Kabul, Afghanistan; fahimi90@gmail.com (R.F.); \\ * Correspondence: Asefiyaser65@gmail.com (Y.A.);
}

Scopus Author ID 57216565685

Received: 19.06.2021; Revised: 25.07.2021; Accepted: 28.07.2021; Published: 8.08.2021

\begin{abstract}
The present study aimed to explore the synergistic anticancer effect of combined L-ascorbic acid (LAA) with superparamagnetic iron oxide nanoparticles (SPIONs) on adenocarcinoma gastric cell line (AGS). $\mathrm{Fe}_{3} \mathrm{O}_{4}$-LAA was synthesized using the reverse co-precipitation technique. XRD, FT-IR, FESEM, and TEM were employed to characterize the synthesized nanoparticles. MTT test and Realtime PCR were performed to investigate the cytotoxicity and apoptosis induced by treatments. The present study indicated that the anticancer properties of vitamin $\mathrm{C}$ were increased when employed as the $\mathrm{Fe} 3 \mathrm{O} 4-\mathrm{LAA}$ nanoparticles. A dose-dependent manner on the effect of $\mathrm{Fe}_{3} \mathrm{O}_{4}$ - $\mathrm{LAA}$ on investigated genes was observed; p53 gene expression changes in high and low doses of $\mathrm{Fe}_{3} \mathrm{O}_{4}$-LAA were 7.4 and 3.1 fold, respectively; accordingly, Bcl2 gene expression under treatment with high and low doses of Fe3O4-LAA was reduced by $71 \%$ and $25 \%$, respectively. In conclusion, our results indicated that Fe3O4-LAA nanoparticles might be an efficient agent for cancer treatment.
\end{abstract}

Keywords: vitamin C; superparamagnetic iron oxide nanoparticles; cancer.

(C) 2021 by the authors. This article is an open-access article distributed under the terms and conditions of the Creative Commons Attribution (CC BY) license (https://creativecommons.org/licenses/by/4.0/).

\section{Introduction}

Despite the many novel insights from cancer research, currently available treatments are still ineffective. Cancer remains one of the main public health problems, with an estimated about 9.6 million deaths in 2018 worldwide [1]. Over the last decades, nanomaterials with fewer than 100 nanometers due to their superior characteristics compared to their respective bulk material have gained great attention as therapeutic and diagnostic agents in cancer research. Apart from that, nanomaterials are widely used as efficient carriers for targeted delivery of therapeutic agents, resulting in increased efficacy and decreased side effects [2-4]. Superparamagnetic iron oxide nanoparticles (SPIONs) are some of the very promising nanoparticles in this field because of their low toxicity, biocompatibility, and unique magnetic properties [5]. SPIONs have been widely used as contrast agents. However, their ability to target key molecules that control cancer progressions such as p53 and Bcl-2 also revealed their therapeutic potentials [6].

In recent years, a growing number of studies have been performed to develop multifunctional SPIONs [7]. However, their accumulation and difficulty in dispersing in aqueous media have limited their application. To tackle this problem, several strategies such 
as polymeric surface coating have been widely investigated and showed to be efficient in improving the SPIONs dispersing in aqueous media [8]. Furthermore, these coating options increased the anticancer properties of SPIONs [9].

Ascorbic Acid (AA), usually mentioned as Vitamin C, is water-soluble and widely used as a biocompatible surfactant for SPIONs [10]. Vitamin C also showed the anticancer properties via up-regulation of p53 and down-regulation of Bcl-2, resulting in the induction of apoptosis [11-13]. However, its use as an anticancer agent is limited due to the requirement of a high dose, which is not achievable under physiological conditions [14]. Therefore, combining Vitamin $\mathrm{C}$ with other anticancer agents to improve its anticancer properties has attracted considerable attention[15]. We herein aimed to investigate the possible synergistic anticancer effects of SPIONs coated with Vitamin $\mathrm{C}$ in the adenocarcinoma gastric cell line (AGS) by assessing the expression of two p53 and Bcl-2 genes.

\section{Materials and Methods}

\subsection{Nanoparticle preparation.}

A reverse co-precipitation approach was employed to produce iron oxide nanoparticles, as previously reported [16]. Briefly, aqueous solutions of $\mathrm{FeCl}_{3}$ and $\mathrm{FeCl}_{2}$ were prepared and added to $100 \mathrm{ml} 10 \mathrm{~N}$ deaerated ammonium hydroxide solutions, and then magnetite nanoparticles (MNPs) were obtained by stirring the solution under argon atmosphere for 30 min. Vitamin $\mathrm{C}$ acid coating of the MNPs was done by adjusting the solution $\mathrm{pH}$ to 12.5 and adding $0.5 \mathrm{~g}$ of vitamin $\mathrm{C}$.

\subsection{Nanoparticle characterization.}

The crystalline structure of the samples was assessed using X-Ray Diffraction (XRD) patterns; (Philips Xpert X-ray diffractometer with $\mathrm{Cu} \mathrm{K} \propto$ radiation $(\lambda=0.15406 \mathrm{~nm})$ ). Size and morphology of NPs were examined by Field Emission Scanned Electron Microscope (FESEM, Hitachi S-4800) and high-resolution Transmission Electron Microscopy (TEM, Zeiss-EM10C-100 kV, Germany) at an accelerating voltage of $150 \mathrm{kV}$. The presence of a coating on the surface of NPs was determined by Fourier-Transform Infrared Spectroscopy (FT-IR, Perkin Elmer Spectrum RX I apparatus) to record the redox reaction UV-Vis (Scinco 4100 apparatus) spectra were employed.

\subsection{Treatment and MTT test.}

Cell counts were performed by a hemocytometer, and 10000 cells were applied for all experiments. To calculate $\mathrm{LD} 50$, cells treated with $\mathrm{Fe}_{3} \mathrm{O}_{4}-\mathrm{LAA}, \mathrm{Fe}_{3} \mathrm{O}_{4}$, and vitamin $\mathrm{C}$ were added to each well ( 60 wells on a 96 well plate), and the plate was returned to the incubator for either 24, 48, or 72 hours. Each treatment was performed with 6 replicates, each of which was performed at 9 different concentrations. The first row in each pellet was treated as control with 6 replicates. Anti-tumor properties on the AGS cell line were assessed using 3-4, 5dimethylthiazol-2-yl 2,5-iphenyltetrazolium bromide (MTT) colorimetric assay. After 24, 48, or $72 \mathrm{~h}$ following the treatment, MTT reagent was added to each well, and the plate was then incubated for an additional $4 \mathrm{~h}$ at $37^{\circ} \mathrm{C}$, followed by adding $20 \mu \mathrm{l}$ of MTT solution $(5 \mathrm{mg} / \mathrm{ml}$ in PBS) to each well. The plate was then incubated for a further $4 \mathrm{~h}$ followed by adding $200 \mu \mathrm{l}$ of MTT solvent and was shacked for 10 minutes. Then, spectrophotometric absorbance was 
measured at $570 \mathrm{~nm}$ and read by an ELISA reader. The Optical Density (OD) was measured for each well.

\subsection{RNA extraction and complementary DNA synthesis.}

RNA was extracted from negative control samples and two high doses and two low doses of LD50 for both treated MNPs and vitamin C. Then, samples were centrifuged for 2 minutes / $12000 \mathrm{~g}$, and the supernatant was removed. RNA extraction was performed using RNX- Plus Solution (EX6101, Sinaclon, Iran). After centrifugation, the sediment was stored at $-80^{\circ} \mathrm{C}$ until analyses. The complement DNA (cDNA) was synthesized using a cDNA synthesis kit (Sinaclon, Iran).

\subsection{Real-time polymerase chain reaction.}

Real-time PCR was done using a Corbett Rotor-Gene 3000 (Corbett Robotics, Australia) with the application of Eva Green Premix Ex Taq II (BioFact, Daejeon, Korea). The specific primers used in the present study are reported in Table 1. PCR mixtures included $1 \mu \mathrm{L}$ of the first-strand cDNA, $10 \mu \mathrm{L}$ of Eva Premix Ex Taq II $(2 \times), 8 \mu \mathrm{L}$ of DEPC-treated water, and $1 \mu \mathrm{L}$ of each specific primers $(10 \mathrm{pmol}$ in a final volume of $20 \mu \mathrm{L})$.

Table 1. Primers sequence.

\begin{tabular}{l|l|l|l} 
Gene & Sense $\mathbf{5}^{\prime} \mathbf{3}^{\prime}$ & Antisense $\mathbf{5}^{\prime} \cdot \mathbf{3}^{\prime}$ & $\begin{array}{l}\text { Product } \\
\text { size (bp) }\end{array}$ \\
\hline GAPDH & CAAGGTCATCCATGACAACTTTG & GTCCACCACCCTGTTGCTGTAG & 496 \\
\hline P53 & CAGTGCTCGCTTAGTGCTCC & GTGTTTGTGCCTGTCCTGGG & 107 \\
\hline Bcl2 & GAGGCAGGCAGTAGTATGGTG & AGGATAACGGAGGCTGGACA & 100
\end{tabular}

Temperature conditions consisted of initial denaturation at $95^{\circ} \mathrm{C}$ for 10 minutes, followed by 40 cycles of denaturation at $95^{\circ} \mathrm{C}$ for 15 seconds, annealing at $60^{\circ} \mathrm{C}$ for 40 seconds, and extension at $72^{\circ} \mathrm{C}$ for 30 seconds. The relative expression levels of investigated genes were normalized to glyceraldehyde-3-phosphate dehydrogenase (GAPDH) as the endogenous housekeeping gene. The relative value of $\mathrm{Ct}$ was compared to that of control cells as a reference for estimating the fold change of mRNA expression among the samples. Triplicates were conducted for each pair of primers. The primers required for the reaction were designed by Primer 3 software. The results were analyzed using $2^{-\Delta \Delta C}$ T method.

\subsection{Statistical analysis.}

SPSS Version 23 statistic software package was used for statistical analyses. P $<0.05$ was considered significant.

\section{Results and Discussion}

\subsection{FTIR analysis.}

FTIR spectrums of the MNPs and MNPs coated with vitamin C are shown in Figure 1. FTIR analysis was applied to assess the possible functional group attached to the surface of the synthesized nanoparticles. FT-IR spectra were also recorded to determine the functional groups of the samples within the range of $400-4000 \mathrm{~cm}^{-1}$ using the $\mathrm{KBr}$ (potassium bromide) method, in which the absorptions at $1113 \mathrm{~cm}^{-1}, 1316 \mathrm{~cm}^{-1}$, and $1360 \mathrm{~cm}^{-1}$ were related to $\mathrm{C}-\mathrm{O}$ groups. 
Meanwhile, an additional band around $1628 \mathrm{~cm}^{-1}$ could be attributed to the stretching vibrations of $\mathrm{C}=\mathrm{C}$ groups, indicating the presence of the vitamin $\mathrm{C}$ constituent.

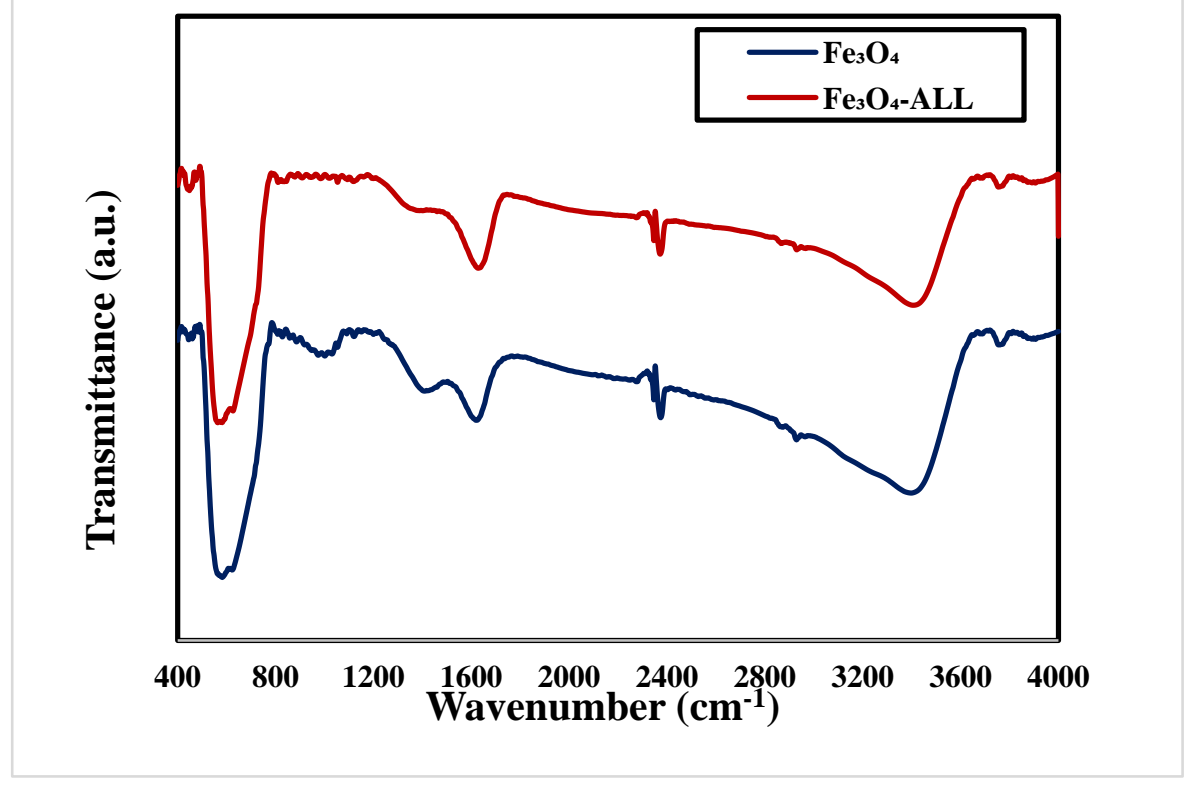

Figure 1. Fourier-transform infrared spectra of $\mathrm{Fe}_{3} \mathrm{O}_{4}$ and $\mathrm{Fe}_{3} \mathrm{O}_{4}-\mathrm{ALL}$.

Figure 2 displays the X-ray diffraction patterns of MNPs and MNPs coated with vitamin C. The mentioned figure shows a typical XRD spectrum of $\mathrm{Fe} 3 \mathrm{O} 4$ nanoparticles, and all peaks can be indexed as a pure $\mathrm{Fe} 3 \mathrm{O} 4$ phase with an inverse spinel structure and matched well with the reported data (JCPDS:65-3107). The average crystallite size calculated by Scherrer formula and full-width-at-half-maximum (FWHM) of the strongest peak (3 111$)$ was $15 \mathrm{~nm}$. The figure presents peaks at $2 \theta$ of $30.22^{\circ}, 35.4^{\circ}, 43.12^{\circ}, 57^{\circ}$, and $62.84^{\circ}$.

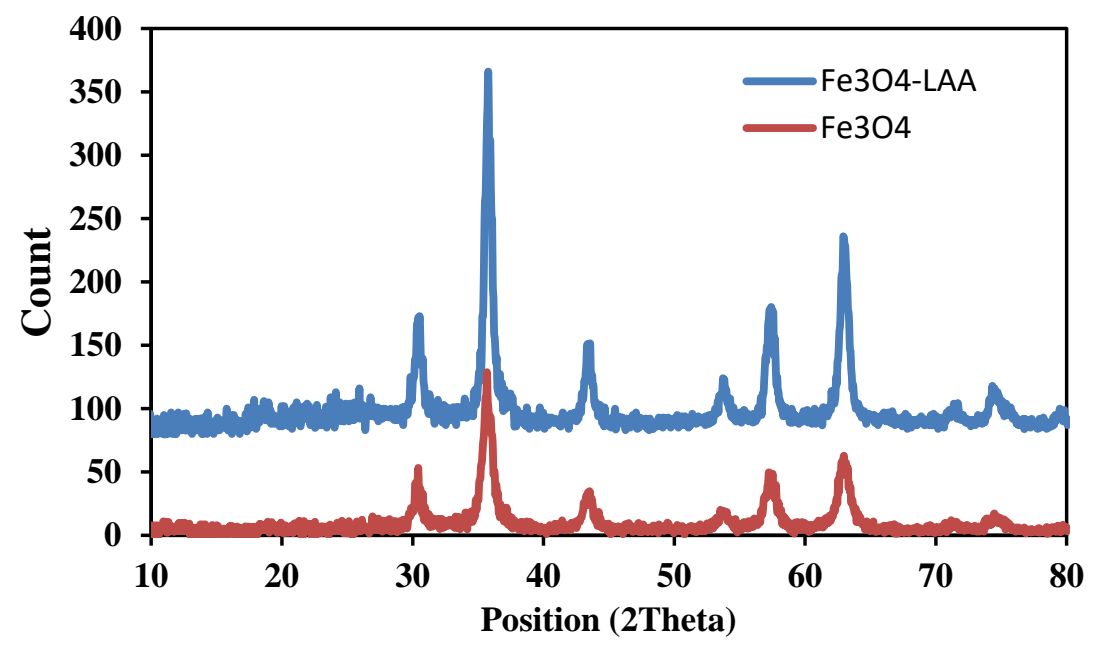

Figure 2. X-ray diffraction pattern.

\subsection{Electron microscopy.}

The morphology and size of the nanoparticles examined by electron microscopy techniques are presented in Figure 3. A low magnification FESEM image (see Figures 3a) showed circular plates of uniform size sorted in various directions, which provided morphologies similar to flowers. Higher magnifications were obtained using the TEM analysis (Figure 3b). The findings revealed regular and uniform particles with a diameter of $20 \mathrm{~nm}$. 

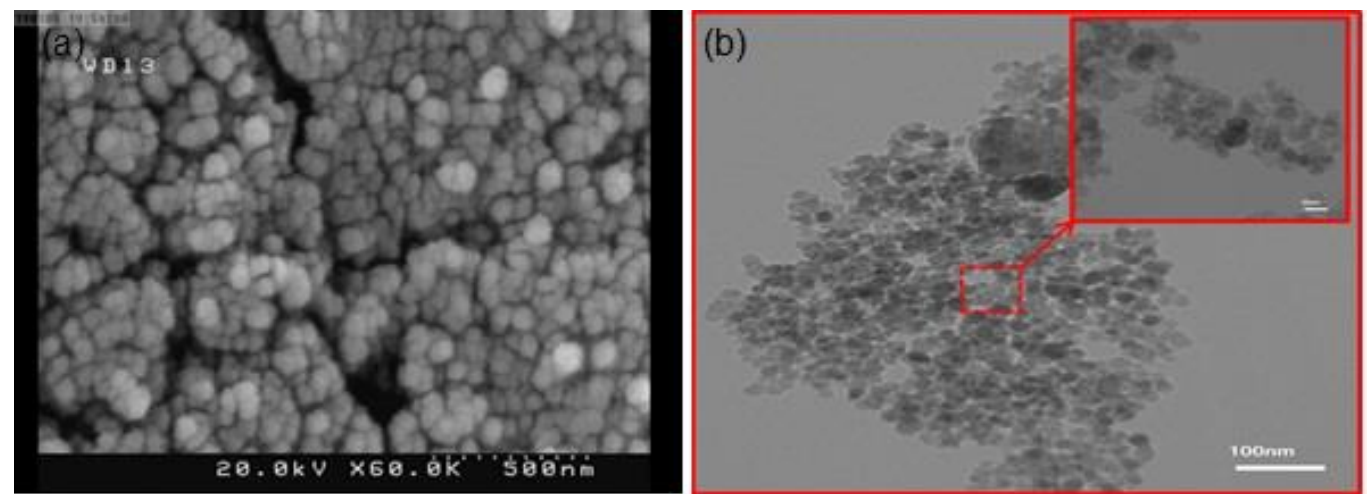

Figure 3. (a) FESEM images and (b) TEM images of $\mathrm{Fe}_{3} \mathrm{O}_{4}$-LAA nanoparticles.

\subsection{MTT analysis.}

Results of MTT analysis showed a significant difference in the cell viability between $\mathrm{Fe}_{3} \mathrm{O}_{4}-\mathrm{LAA}, \mathrm{Fe}_{3} \mathrm{O}_{4}$, and vitamin $\mathrm{C}$ after $48 \mathrm{~h}$; cell viability had the lowest rate in $\mathrm{Fe}_{3} \mathrm{O}_{4}$-LAA and vitamin $\mathrm{C}$ group, and treatments by $\mathrm{Fe} 3 \mathrm{O} 4$ had no cytotoxicity impact on the AGS cells. Interestingly a dose-dependent reduction in cell viability was observed by increasing the doses of Fe3O4-LAA and vitamin $\mathrm{C}(\mathrm{P}<0.05)$ (shown in Figures 4 and 5). The concentrations of each agent giving 50\% inhibition of cell viability (IC50) were estimated using the IC50 calculation software. The IC50 value for Fe3O4-LAA and vitamin C was calculated as $48 \mu \mathrm{g} / \mathrm{ml}$ and 29 $\mu \mathrm{g} / \mathrm{ml}$, respectively.

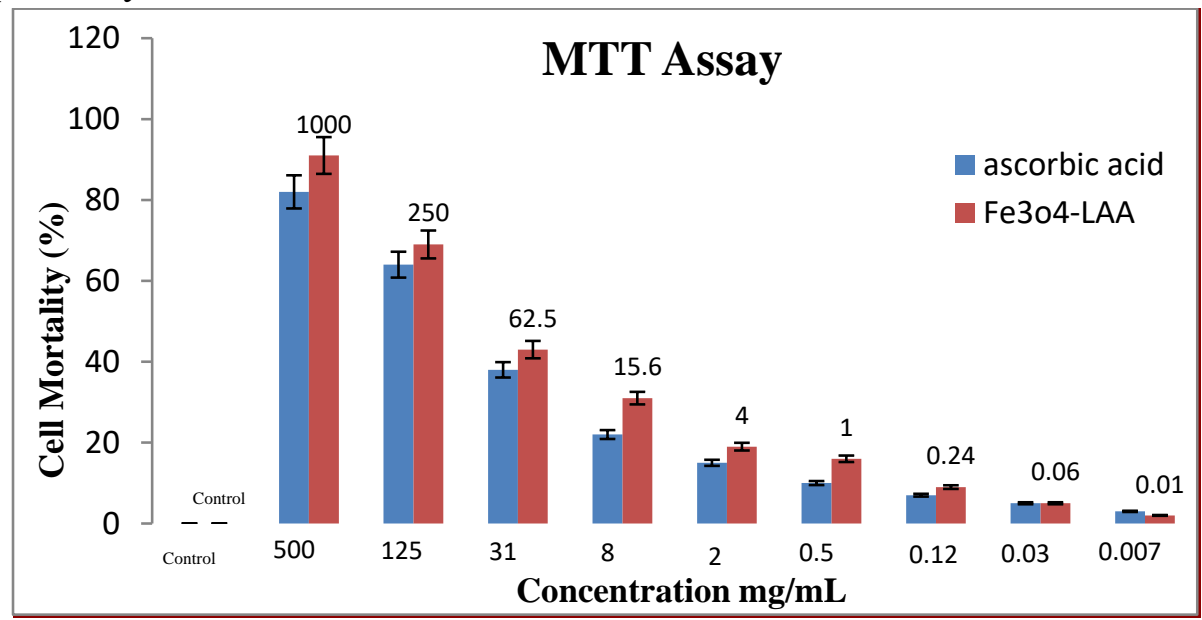

Figure 4. The effect of different concentrations of $\mathrm{Fe}_{3} \mathrm{O}_{4}$-LAA and vitamin $\mathrm{C}$ on the mortality of AGS cell line using MTT assay $(\mathrm{P}<0.05)$.
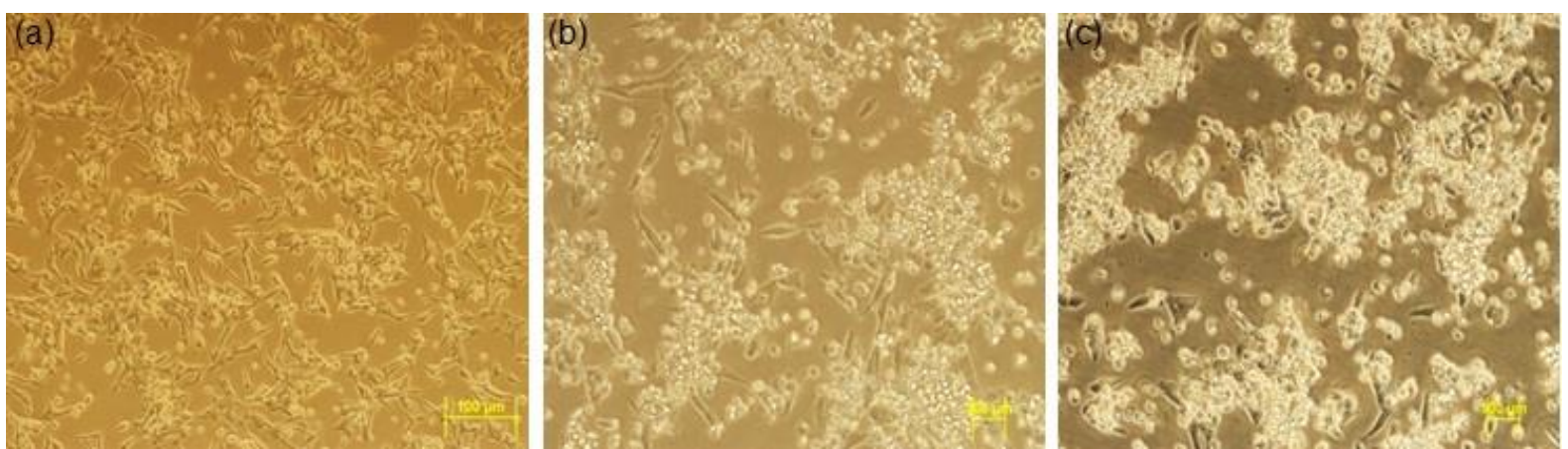

Figure 5. Inverted photo from AGS cell line (a) Without treatment; (b) With treatment by vitamin C; (c) With treatment by $\mathrm{Fe}_{3} \mathrm{O}_{4}$-LAA. 


\subsection{P53 and Bcl2 genes expression.}

Changes in the expression of investigated genes following treatment with different concentrations of ascorbic acid and MNPs are given in Figures 6 and 7. Our founding showed that $\mathrm{p} 53$ and $\mathrm{Bcl} 2$ expressions were significantly $(\mathrm{P}<0.05)$ increased and decreased respectively in MNPs and vitamin $\mathrm{C}$ groups compared to the control group. Furthermore, these changes were more notable in high doses; the rates of p53 gene expression in high and low doses of MNPs were 7.4 fold and 3.1 fold, respectively. Accordingly, the rates of $\mathrm{Bcl} 2$ gene expression under treatment with high and low doses of MNPs reduced by $71 \%$ and $25 \%$, respectively. In the vitamin $\mathrm{C}$ group, the rates of p53 gene expression in high and low doses were 9.8 fold and 2.2 fold, respectively, and the rates of $\mathrm{Bcl} 2$ gene expression in high and low doses were reduced by $81 \%$ and $19 \%$, respectively.

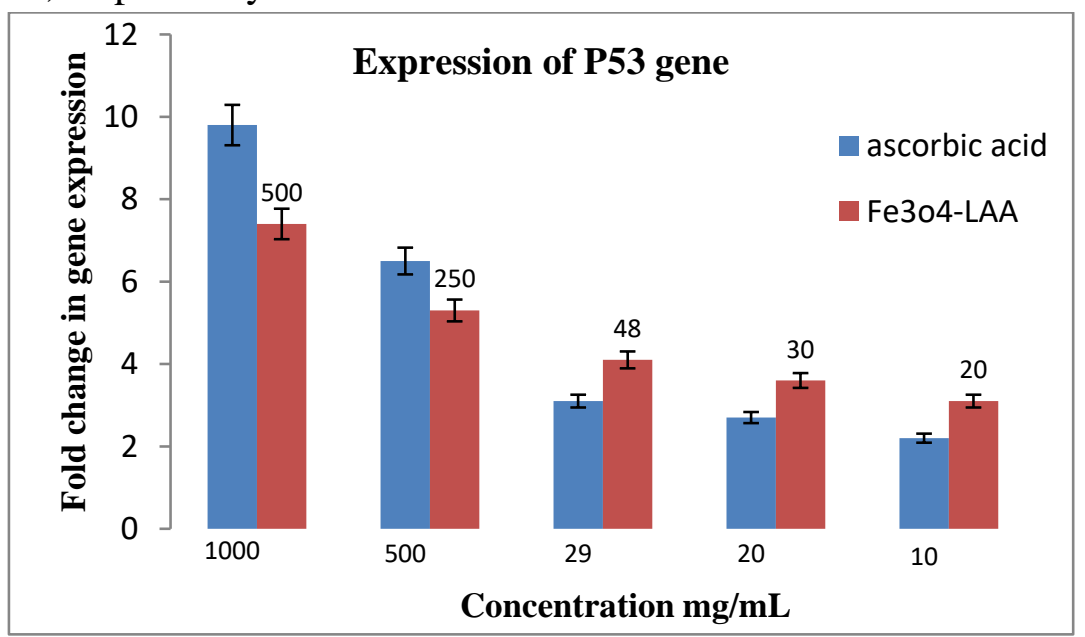

Figure 6. Expression of P53 gene following the treatment with different concentrations of $\mathrm{Fe}_{3} \mathrm{O}_{4}-\mathrm{LAA}$ and vitamin C.

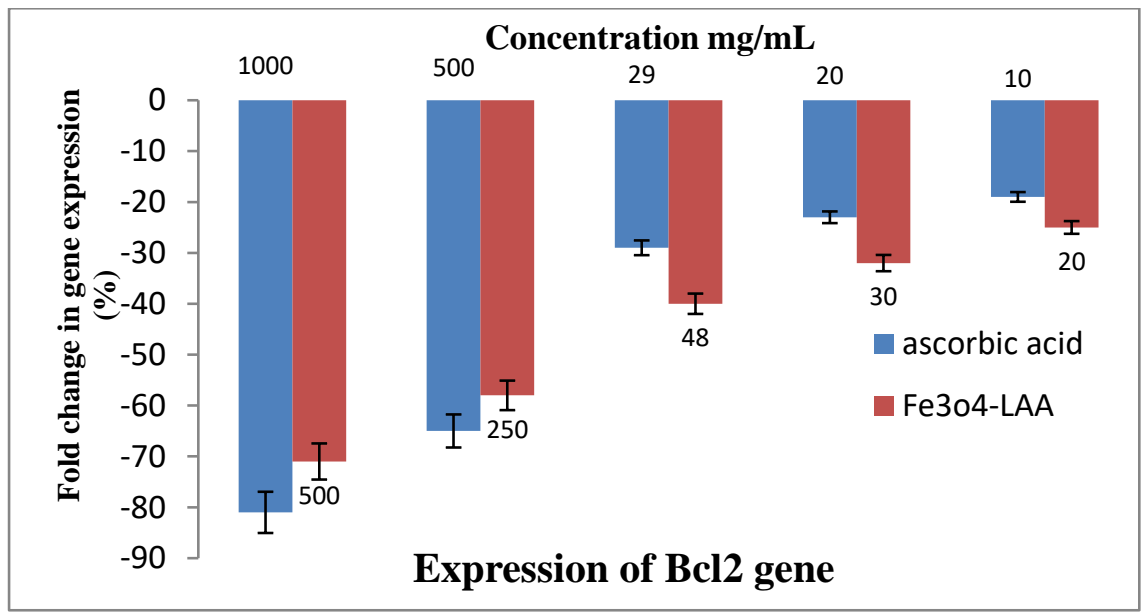

Figure 7. Expression of $\mathrm{Bcl} 2$ gene following the treatment with different concentrations of $\mathrm{Fe}_{3} \mathrm{O}_{4}-\mathrm{LAA}$ and vitamin C.

Ascorbic acid proved to be an efficient anticancer agent; however, its application has been limited due to its low bioavailability and high dose requirement [15,17]. Using nanoparticles as carriers can help stabilize the chemical form of ascorbic acid and prevent its oxidative transformation to dehydroascorbic acid. Moreover, it reduces the high doses requirement with targeted delivery [18]. On the other side, SPIONs also showed anticancer properties. However, their very low solubility and consequently oxidization and aggregation 
together limited their wide application [6]. Therefore we herein synthesized SPIONs capped with L-ascorbic acid in order to enhance their bioavailability and anticancer effects.

Results of the present study showed that AGS cells treatment for 48 hours with SPIONs capped with ascorbic acid-induced AGS cell death more than ascorbic acid and increasing the dose of SPIONs and ascorbic acid enhanced the mortality rate, and the highest dose had the maximum effect on cancer cell death. These results were in consistent with previously published results about the cytotoxicity effect of SPIONs and ascorbic acid on different cancer cells $[19,20]$. Herein we showed that a combination of these agents increased their cytotoxicity effects.

One of the mechanisms underlying the cytotoxic activity of vitamin C and SPIONs in cancer cells is induced oxidative stress. In addition to cellular toxicity, a high level of SPIONs indicates a remarkable decrease in peroxide levels, demonstrating that it becomes a more harmful cell species as radical hydroxyl or nitrite peroxide [17,21]. Although these reactive species were not measured in this study, the mentioned point can be a logical justification as hydrogen peroxide can be converted to radical hydroxyl by the reaction of Fenton-Habber Weiss in the presence of free iron and the anion of superoxide in the presence of nitric oxide can yield Nitrite peroxide [22]. The findings of this study are in line with those of Pires et al.'s study, which showed that active species caused damage to cells, but vitamin $\mathrm{C}$ reduced free radicals and reactive oxygen species [23]. Moreover, ascorbic acid has been reported to act as an antioxidant to preserve the balance of intrinsic cellular and minimize the oxidative damage produced by gathering reactive oxygen species [24]. An imbalance between antioxidant defense and oxidative stress can result in cancer [25]. Thus ascorbic acid magnetite nanoparticles play an important role in preventing cancer via the upregulation of apoptosis genes.

It is of great value to recognize the molecular mechanism by which nanoparticles could control cancer cells because new anticancer medicines are based on molecular therapies that are designed against specific pathways. Hence, the impacts of SPIONs could be enhanced if they are related to drugs targeting altered genes or proteins. In this regard, the expression of BCL2 and p53 genes, which play a significant role in inhibiting cell proliferation via stopping the cell cycle and inducing apoptosis [26], were examined. The findings (Figures 6 and 7) indicated that nanoparticles and ascorbic acid significantly increased the p53 expression and reduced the expression of BCL2 gene in cancer cells as compared to the control group. In addition, doses also had a remarkable effect on the expression of genes so that higher doses, as compared with low doses, in p53 and BCL2 had respectively increased and decreased expression levels. This study's findings agree with those of Bassiony et al.'s study, which reported that nanoparticles hindered the tumor through the upregulation of apoptosis genes [6]. Oxidative stress takes place when an excessive production of active species occurs due to an external (e.g., ultraviolet radiation) or an internal (at the cellular level involved in mitochondria) source [27]. The ascorbic acid magnetite nanoparticles are involved in the scavenging of these species [24]. The most important mechanism justifying the impact of nanoparticles on the expression of p53 and BCL2 is through its antioxidant property, which enhances the expression of genes involved in the apoptosis, decreases free radicals, regulates cellular signaling, regulates cell cycle, regulates the reaction of oxidation, and restores and prevents mutation [28,29]. In vivo and in vitro experiments reveal that antioxidants could impede the growth of neoplastic cells, induce apoptosis, stimulate cell differentiation, and inhibit protein kinase $\mathrm{C}$ and adenylyl cyclase [30,31]. 
Vitamin $\mathrm{C}$ is shown to increase the expression of pro-apoptotic proteins such as Bax and P53 and decrease the antiapoptotic Bcl-2 protein expression, thereby resulting in cell death. Signaling between P53 and Bcl-2 has been showing to be of high significance for cancer screening. P53 gene is activated in several cellular stresses and acts as an intermediary to stop the cell cycle [32]. Besides, the activation of Bax by P53 might overcome the antiapoptotic influences of Bcl-2 [33]. Thus, regulating the P53 mediator of the Bax ratio to the Bcl-2 level could affect cell function during stress response [34,35]. Furthermore, cancer cells often display an excessive expression of the Bcl-2 protein, which prevents the cytochrome release of mitochondria, provides the cell with chemotherapy resistance, and avoids apoptosis [36].

\section{Conclusions}

In conclusion, the current study revealed that a combination of SPIONs with ascorbic acid increased the anticancer effect of vitamin $\mathrm{C}$ and effectively inhibited cancer cells growth and induced apoptosis through altering the expression of p53 and BCL2 genes. Thus, applying these compounds might effectively treat cancers when high doses of vitamin $\mathrm{C}$ cannot be applied.

\section{Funding}

This research received no external funding.

\section{Acknowledgments}

We want to express our sincere gratitude to the anonymous reviewers for their valuable comments and suggestions to improve the paper's quality.

\section{Conflicts of Interest}

The authors declare no conflict of interest.

\section{References}

1. Abyadeh, M.; Meyfour, A.; Gupta, V.; Zabet Moghaddam, M.; Fitzhenry, M.J.; Shahbazian, S.; Hosseini Salekdeh, G.; Mirzaei, M. Recent Advances of Functional Proteomics in Gastrointestinal Cancers-a Path towards the Identification of Candidate Diagnostic, Prognostic, and Therapeutic Molecular Biomarkers. International Journal of Molecular Sciences 2020, 21, 8532, https://doi.org/10.3390/ijms21228532.

2. Cheng, H.W.; Tsao, H.Y.; Chiang, C.S.; Chen, S.Y. Advances in Magnetic Nanoparticle-Mediated Cancer Immune-Theranostics. Advanced Healthcare Materials 2021, 10, 2001451, https://doi.org/10.1002/adhm.202001451.

3. Abyadeh, M.; Aghajani, M.; Mahmoudabad, A.G.; Amani, A. Preparation and Optimization of Chitosan/pDNA Nanoparticles Using Electrospray. Proceedings of the National Academy of Sciences, India Section B: Biological Sciences 2019, 89, 931-937, https://doi.org/10.1007/s40011-018-1009-6.

4. Abyadeh, M.; Zarchi, A.A.K.; Faramarzi, M.A.; Amani, A. Evaluation of factors affecting size and size distribution of chitosan-electrosprayed nanoparticles. Avicenna journal of medical biotechnology 2017, 9 , 126.

5. Gui, G.; Fan, Z.; Ning, Y.; Yuan, C.; Zhang, B.; Xu, Q. Optimization, Characterization and in vivo Evaluation of Paclitaxel-Loaded Folate-Conjugated Superparamagnetic Iron Oxide Nanoparticles. International Journal of Nanomedicine 2021, 16, 2283, https://doi.org/10.2147/IJN.S287434.

6. Bassiony, H.; Sabet, S.; El-Din, T.A.S.; Mohamed, M.M.; El-Ghor, A.A. Magnetite nanoparticles inhibit tumor growth and upregulate the expression of P53/P16 in Ehrlich solid carcinoma bearing mice. PloS one 2014, 9, e111960, https://doi.org/10.1371/journal.pone.0111960.

7. Qin, M.; Xu, M.; Niu, L.; Cheng, Y.; Niu, X.; Kong, J.; Zhang, X.; Wei, Y.; Huang, D. Multifunctional modification of Fe $3 \mathrm{O} 4$ nanoparticles for diagnosis and treatment of diseases: A review. Frontiers of Materials Science 2021, 1-18, https://doi.org/10.1007/s11706-021-0543-y. 
8. Larsen, E.K.U.; Nielsen, T.; Wittenborn, T.; Rydtoft, L.M.; Lokanathan, A.R.; Hansen, L.; Østergaard, L.; Kingshott, P.; Howard, K.A.; Besenbacher, F. Accumulation of magnetic iron oxide nanoparticles coated with variably sized polyethylene glycol in murine tumors. Nanoscale 2012, 4, 2352-2361, DOI: 10.1039/c2nr11554a.

9. Jacob, J.A.; Salmani, J.M.M.; Chen, B. Magnetic nanoparticles: mechanistic studies on the cancer cell interaction. Nanotechnology Reviews 2016, 5, 481-488, https://doi.org/10.1515/ntrev-2016-0022.

10. Özel, F.; Karaagac, O.; Tokay, E.; Köçkar, F.; Köçkar, H. A simple way to synthesize tartaric acid, ascorbic acid and their mixture coated superparamagnetic iron oxide nanoparticles with high saturation magnetisation and high stability against oxidation: Characterizations and their biocompatibility studies. Journal of Magnetism and Magnetic Materials 2019, 474, 654-660, https://doi.org/10.1016/j.jmmm.2018.11.025.

11. An, S.-H.; Kang, J.-H.; Kim, D.-H.; Lee, M.-S. Vitamin C increases the apoptosis via up-regulation p53 during cisplatin treatment in human colon cancer cells. BMB reports 2011, 44, 211-216, DOI: 10.5483/BMBRep.2011.44.3.211.

12. Nematollahi, H.; Gh, H.; Jorat, M. The Effect of Vitamin C on Apoptosis and Bax/Bcl-2 Proteins Ratio in Peripheral Blood Lymphocytes of Patients during Cardiac Interventional Procedures. Journal of Biomedical Physics \& Engineering 2020, 10, 421, DOI: 10.31661/JBPE.V0I0.917.

13. Caritá, A.C.; Fonseca-Santos, B.; Shultz, J.D.; Michniak-Kohn, B.; Chorilli, M.; Leonardi, G.R. Vitamin C: One compound, several uses. Advances for delivery, efficiency and stability. Nanomedicine: Nanotechnology, Biology and Medicine 2020, 24, 102117, https://doi.org/10.1016/j.nano.2019.102117.

14. Pal, S.; Jana, N.R. Pharmacologic Vitamin C-Based Cell Therapy via Iron Oxide Nanoparticle-Induced Intracellular Fenton Reaction. ACS Applied Nano Materials 2020, 3, 1683-1692, https://doi.org/10.1021/acsanm.9b02405.

15. Cho, S.; Chae, J.S.; Shin, H.; Shin, Y.; Kim, Y.; Kil, E.-J.; Byun, H.-S.; Cho, S.-H.; Park, S.; Lee, S. Enhanced anticancer effect of adding magnesium to vitamin $\mathrm{C}$ therapy: inhibition of hormetic response by SVCT-2 activation. Translational oncology 2020, 13, 401-409, https://doi.org/10.1016/j.tranon.2019.10.017.

16. Sreeja, V.; Jayaprabha, K.; Joy, P. Water-dispersible ascorbic-acid-coated magnetite nanoparticles for contrast enhancement in MRI. Applied Nanoscience 2015, 5, 435-441, https://doi.org/10.1007/s13204-0140335-0.

17. Kaźmierczak-Barańska, J.; Boguszewska, K.; Adamus-Grabicka, A.; Karwowski, B.T. Two Faces of Vitamin C-Antioxidative and Pro-Oxidative Agent. Nutrients 2020, 12, 1501, https://doi.org/10.3390/nu12051501.

18. Chakraborty, A.; Jana, N.R. Vitamin C-conjugated nanoparticle protects cells from oxidative stress at low doses but induces oxidative stress and cell death at high doses. ACS applied materials \& interfaces 2017, 9, 41807-41817, https://doi.org/ 10.1021/acsami.7b16055.

19. Lim, J.Y.; Kim, D.; Kim, B.R.; Jun, J.S.; Yeom, J.S.; Park, J.S.; Seo, J.H.; Park, C.H.; Woo, H.O.; Youn, H.S. Vitamin C induces apoptosis in AGS cells via production of ROS of mitochondria. Oncology letters 2016, 12, 4270-4276, https://doi.org/10.3892/ol.2016.5212.

20. Satari, M.; Haghighat, N.; Javani Jouni, F.; Abodolmaleki, P. The Effects of Synthesized Superparamagnetic Iron Oxide Nanoparticles and Electromagnetic Field on Cell Death of MCF-7 Breast Cancer Cell Line. Multidisciplinary Cancer Investigation 2018, 2, 13-21, https://doi.org/10.30699/acadpub.mci.2.1.13.

21. Alarifi, S.; Ali, D.; Alkahtani, S. Oxidative stress-induced DNA damage by manganese dioxide nanoparticles in human neuronal cells. BioMed research international 2017, 2017, https://doi.org/10.1155/2017/5478790.

22. Mamede, A.C.; Pires, A.S.; Abrantes, A.M.; Tavares, S.D.; Gonçalves, A.C.; Casalta-Lopes, J.E.; SarmentoRibeiro, A.B.; Maia, J.M.; Botelho, M.F. Cytotoxicity of ascorbic acid in a human colorectal adenocarcinoma cell line (WiDr): in vitro and in vivo studies. Nutrition and cancer 2012, 64, 1049-1057, https://doi.org/10.1080/01635581.2012.713539.

23. Pires, A.S.; Marques, C.R.; Encarnação, J.C.; Abrantes, A.M.; Marques, I.A.; Laranjo, M.; Oliveira, R.; Casalta-Lopes, J.E.; Gonçalves, A.C.; Sarmento-Ribeiro, A.B. Ascorbic acid chemosensitizes colorectal cancer cells and synergistically inhibits tumor growth. Frontiers in physiology 2018, 9, 911, https://doi.org/10.3389/fphys.2018.00911.

24. Mata, A.M.O.F.d.; Carvalho, R.M.d.; Alencar, M.V.O.B.d.; Cavalcante, A.A.d.C.M.; Silva, B.B.d. Ascorbic acid in the prevention and treatment of cancer. Revista da Associação Médica Brasileira 2016, 62, 680-686, https://doi.org/10.1590/1806-9282.62.07.680.

25. Hu, J.; Liu, S. Modulating intracellular oxidative stress via engineered nanotherapeutics. Journal of Controlled Release 2020, 319, 333-343, https://doi.org/10.1016/j.jconrel.2019.12.040.

26. Bai, H.-L.; Kang, C.-M.; Sun, Z.-Q.; Li, X.-H.; Dai, X.-Y.; Huang, R.-Y.; Zhao, J.-J.; Bei, Y.-R.; Huang, X.Z.; Lu, Z.-F. TTDA inhibited apoptosis by regulating the p53-Bax/Bcl2 axis in glioma. Experimental Neurology 2020, 331, 113380, https://doi.org/10.1016/j.expneurol.2020.113380.

27. Abyadeh, M.; Gupta, V.; Chitranshi, N.; Gupta, V.; Wu, Y.; Saks, D.; Wander Wall, R.; Fitzhenry, M.J.; Basavarajappa, D.; You, Y. Mitochondrial dysfunction in Alzheimer's disease-a proteomics perspective. Expert Review of Proteomics 2021, 18, 295-304, https://doi.org/10.1080/14789450.2021.1918550.

28. Abdullah, J.A.A.; Eddine, L.S.; Abderrhmane, B.; Alonso-González, M.; Guerrero, A.; Romero, A. Green synthesis and characterization of iron oxide nanoparticles by pheonix dactylifera leaf extract and evaluation 
of their antioxidant activity. Sustainable Chemistry and Pharmacy 2020, 17, 100280, https://doi.org/10.1016/j.scp.2020.100280.

29. Sandhya, J.; Kalaiselvam, S. Biogenic synthesis of magnetic iron oxide nanoparticles using inedible borassus flabellifer seed coat: Characterization, antimicrobial, antioxidant activity and in vitro cytotoxicity analysis. Materials Research Express 2020, 7, 015045.

30. Gopalakrishna, R.; Gundimeda, U. Antioxidant regulation of protein kinase $\mathrm{C}$ in cancer prevention. The Journal of nutrition 2002, 132, 3819S-3823S, https://doi.org/10.1093/jn/132.12.3819S.

31. Attia, M.; Essa, E.A.; Zaki, R.M.; Elkordy, A.A. An overview of the antioxidant effects of ascorbic acid and alpha lipoic acid (in liposomal forms) as adjuvant in cancer treatment. Antioxidants 2020, 9, 359, https://doi.org/10.3390/antiox9050359.

32. Pisani, C.; Ramella, M.; Boldorini, R.; Loi, G.; Billia, M.; Boccafoschi, F.; Volpe, A.; Krengli, M. Apoptotic and predictive factors by Bax, Caspases 3/9, Bcl-2, p53 and Ki-67 in prostate cancer after 12 Gy single-dose. Scientific reports 2020, 10, 1-10, https://doi.org/10.1038/s41598-020-64062-9.

33. McCurrach, M.E.; Connor, T.M.; Knudson, C.M.; Korsmeyer, S.J.; Lowe, S.W. bax-deficiency promotes drug resistance and oncogenic transformation by attenuating p53-dependent apoptosis. Proceedings of the National Academy of Sciences 1997, 94, 2345-2349, https://doi.org/10.1073/pnas.94.6.2345.

34. Hemann, M.; Lowe, S. The p53-BCL-2 connection. Cell death and differentiation 2006, 13, 1256, https://doi.org/10.1038/sj.cdd.4401962.

35. Anaya-Eugenio, G.D.; Tan, C.Y.; Rakotondraibe, L.H.; de Blanco, E.C.C. Tumor suppressor p53 independent apoptosis in HT-29 cells by auransterol from Penicillium aurantiacobrunneum. Biomedicine \& Pharmacotherapy 2020, 127, 110124, https://doi.org/10.1016/j.biopha.2020.110124.

36. Tian, W.; Wang, Z.; Tang, N.-n.; Li, J.-t.; Liu, Y.; Chu, W.-F.; Yang, B.-F. Ascorbic acid sensitizes colorectal carcinoma to the cytotoxicity of arsenic trioxide via promoting reactive oxygen species-dependent apoptosis and pyroptosis. Frontiers in pharmacology 2020, 11, https://doi.org/10.3389/fphar.2020.00123. 